\title{
Cone Beam Computed Tomography for Detection of Intranasal Foreign Bodies
}

\author{
Muriel JD1, Escobedo $\mathrm{MF}^{2}$, Cobo $\mathrm{T}^{1,2}$, Cobo $\mathrm{JL}^{3}$, Olay $\mathrm{S}^{2}$ and Junquera $\mathrm{S}^{4 *}$ \\ ${ }^{1}$ Instituto Asturiano de Odontología, Oviedo, Spain \\ 2Departamento de Cirugía y Especialidades Médico-Quirúrgicas, Universidad de Oviedo, Spain \\ ${ }^{3}$ Servicio de Cirugía Maxilofacial, Hospital Universitario Central de Asturias, Oviedo, Spain \\ *4Servicio de Radiología, Complejo Hospitalario Universitario de Santiago, Santiago de Compostela, Spain
}

^Correspondence Author: Junquera S, Department of Maxillofacial Surgery, Oviedo University School of Dentistry, Catedrático José Serrrano s/n. 33007, Oviedo, Spain; Tel: +34985103636; E-mail: Junquera@uniovi.es

Received: November 14, 2019; Accepted: November 19, 2019; Published: November 23, 2019, 2019;

\begin{abstract}
Introduction: Intranasal foreign bodies are common among curious young children and include toys and toy parts (beads, marbles), food (corn, beans, peas, seeds, nuts, hamburger, gum), and other small items (paper wads, cotton, erasers, pebbles, screws, sponges button batteries).

Case presentation: A 13-year-old girl presented to our department with a 2-day history of painful swelling in relation to the tooth 26. Orthopantomography and Cone Beam Computed Tomography (CBCT), revealed a hyperdense material in the left nasal cavity. It was a foreign body of irregular morphology, segmented with dimensions of $93 \times 52 \times 38 \mathrm{~mm}$. Under local anesthesia and by direct rhinoscopy a piece of a metal toy were removed.
\end{abstract}

Conclusion: Cone beam computed tomography is a reliable method for the diagnosis of nasal foreign bodies by providing the exact location and composition

Keywords: Cone Beam Computed Tomography, Metal, Nasal Foreign Body

\section{Introduction}

Intranasal Foreign Bodies (FBs) are common among curious young children, with the right nostril favoured by right-hand dominant patients [1]. They are classified as organic FBs (such as nuts, legumes, seeds, or chicken) or inorganic FBs (such as toys, pen tops, battery, or stones/shells). Overall, items of jewellery are the most common foreign bodies requiring removal in children, accounting for up to $40 \%$ of cases. In the nose, jewellery is followed by paper and plastic toys, whereas in the ears, cotton buds and pencils are the most likely culprits after jewellery [2]. Although most foreign bodies in the ears and nose can be easily removed, alimentary or respiratory FBs injuries can have a fatal outcome. In the children, the most common anatomical locations of FB injuries differed according to age. The mean ages of children with various FB injuries were as follows: ear FB injuries, 3.7 years; nose, 2.7 years; alimentary system, 2.2 years; and respiratory system, 2.9 years [3]. In a review of all Emergency Department visits in a 5-year span, there were 6418 (3.2\% of all visits) visits nationwide for management of nasal foreign bodies, only 214 $(0.1 \%)$ of which were adults [4]. French et al recommend in their work that increased efforts should be made to restrict child access to beads, pearls, marbles, button batteries, coins and nuts and seeds [5]. In adult patients, however, the mechanism and force of entry must be considered as there is a greater chance of violation of the skull base and possible cerebrospinal fistula [6].
Intranasal foreign bodies may cause complications such as pain, swelling, inflammation, septal perforation, infection and migration to compromised territories. To prevent these complications, FBs should be detected and extracted promptly. Considering the gap of information on the diagnostic sensitivity of Cone Beam Computed Tomography (CBCT), this study was aimed to assess CBCT's ability to differentiate between metallic foreign bodies and batteries. The button battery should be treated as a life threatening foreign body due to its electrochemical content and rapid tissue damage.

\section{Clinical Presentation}

A 13-year-old girl presented to our department with a 2-day history of painful swelling in relation to the tooth 26. Orthopantomography showed caries in the first left upper molar, and incidentally the presence of a foreign body on the floor of the left nostril (Figure 1). CBCT (Planmeca ProMax 3D Mid) revealed a hyperdense material in the left nasal cavity. It was a foreign body of irregular morphology, segmented with dimensions of $93 \times 52 \times 38 \mathrm{~mm}$ (Figure 2-3). These images allowed the exact location of the foreign body and know that it was not a button battery. The girl did not remember history of foreign body insertion. He reported being asymptomatic, although he noticed a moderate left nasal obstruction for two years before orthopantomography. On examination, there was extensive edema with slough in the left side of the nasal cavity. In the operating room, 
under local anesthesia and by direct rhinoscopy a piece of a metal toy were removed. Septal perforation was not observed.

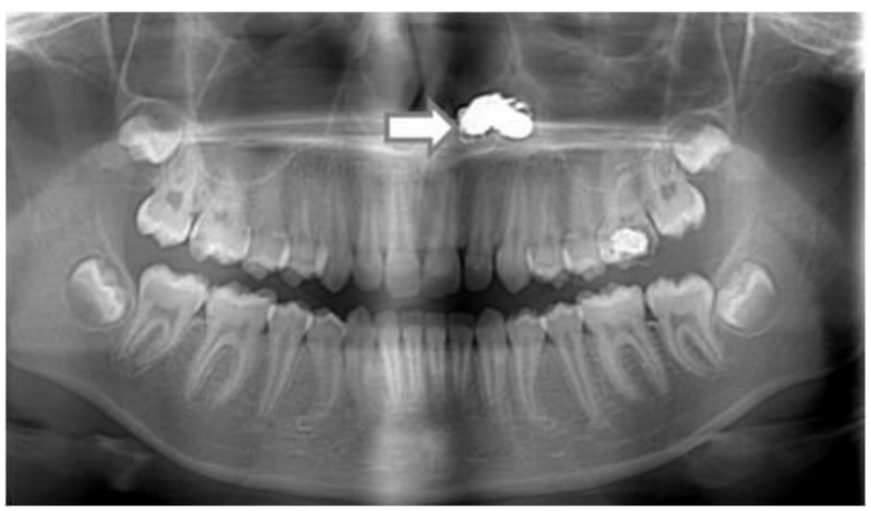

Figure 1. Orthopantomography. Radiodense image of irregular contour on the floor of the left nostril.
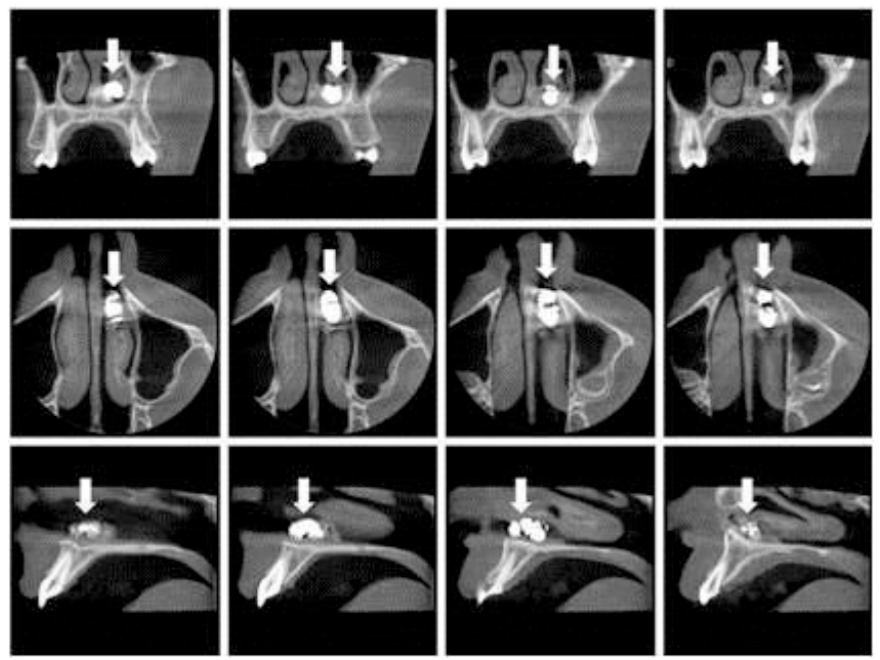

Figure 2. CBCT. Foreign body of irregular morphology, segmented with dimensions of $93 \times 52 \times 38 \mathrm{~mm}$ and without halo sign, common in button batteries.
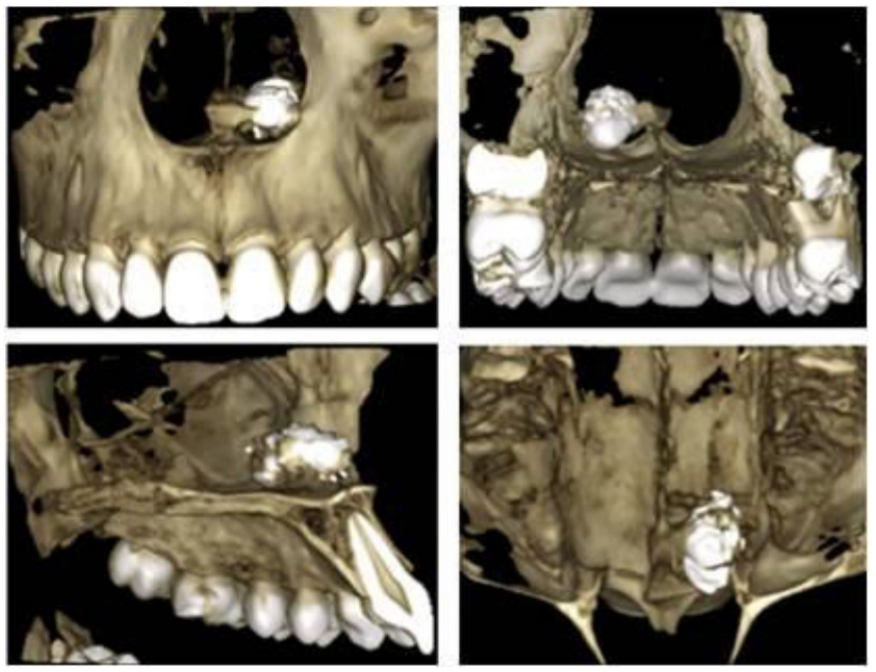

Figure 3. Three-dimensional reconstruction of the foreign body.

\section{Discussion}

Pediatric nasal obstruction is one of the most common problems seen in pediatric otolaryngologists. Typically, this is not an urgent diagnosis but is more commonly associated with reduced quality of life. Allergic rhinitis is one of the most common causes of pediatric nasal obstruction, which affects $8 \%$ to $16 \%$ of children and is immunoglobulin $\mathrm{E}$ mediated. In younger children, nasal foreign bodies must always be on the differential of nasal obstruction. Intervention is always needed for nasal foreign body removal in order to prevent further migration distally, potentially precipitating an airway emergency. The timing of removal is often based on the foreign body involved. Batteries are always considered an emergency because of the complications associated with prolonged exposure (septal perforation, saddle nose deformity, orbital injury, synechiae). However, nasal foreign bodies can often be removed without general anesthesia if the child is cooperative [7]. Alkaline batteries cause extensive necrosis and tissue destruction. Possible mechanisms include spontaneous electrolyte leakage with liquefactive necrosis and destruction of tissue, and generation of electrical current causing an electric burn [8-10].

In our case, unlike many other cases, the nasal foreign body may remain asymptomatic for a long time. Our patient had only a complaint of nasal stuffiness. This is an unusual case of a large chronic nasal foreign body with no known history of insertion. If the patient had indeed had symptoms for the previous two years, this suggests the foreign body was inserted when he was around age 11, which would be unusual in a child without learning disability. Identification and localization of foreign bodies are based on history, clinical and radiographic examinations. Various imaging modalities, including, periapical radiographs, plain radiography, Computed Tomography (CT), and ultrasonography, have been advocated for detecting FBs. Radiographs detected FBs generally considered radiopaque (gravel, glass, metal) in $98 \%$ of cases, but do not detected radiolucent (wood, plastic, cactus spine) bodies. The false-negative and false-positive rates for radiography are $50 \%$ and $1.6 \%$, respectively $[11,12]$. Periapical radiographs are the primary diagnostic aid used in identifying the foreign bodies. However, these are not helpful in the identification of cases, in which foreign body sizes are $<2 \mathrm{~mm}$ or in identifying the exact locations of the objects. These problems can be overcome by advanced diagnostic and imaging aids such as CT, and Cone Beam Computed Tomography. CBCT provides images at low dose with sufficient spatial resolution, which can be applied in diagnosis, treatment planning, and post-treatment evaluation. СBCT has higher spatial resolution and greater ability to detect high-density foreign bodies as small as 0.5 $\mathrm{mm}[13,14]$. In our case discarded the diagnosis of button batteries.

\section{Conclusion}

Within limits of this case report, Cone beam computed tomography is a reliable method for the diagnosis of nasal foreign bodies, by providing the exact location and composition.

\section{References}

1. Grigg S, Grigg C (2018) Removal of ear, nose and throat foreign bodies: A review. Aust J Gen Pract 47: 682-685. 
2. Foltran F, Ballali S, Passali FM, Kern E, Morra B, et al. (2012) Foreign bodies in the airways: a meta-analysis of published papers. Int $J$ Pediatr Otorhinolaryngol 14: $12-19$.

3. Park JW, Jung JH, Kwak YH, Jung JY (2019) Epidemiology of pediatric visits to the emergency department due to foreign body injuries in South Korea: Nationwide cross-sectional study. Medicine (Baltimore) 98: e15838.

4. Svider PF, Sheyn A, Folbe E, Sekhsaria V, Zuliani G, et al. (2014) How did that get there? a population-based analysis of nasal foreign bodies. Int Forum Allergy Rhinol 4: 944-949.

5. French MA, Lorenzoni G, Purnima, Azzolina D, Baldas S, et al. (2019) Foreign Body injuries in children in India: Recommendations for prevention from a comparative analysis with international experience. Int J Pediatr Otorhinolaryngol 124: 6-13.

6. Gray ML, Kappauf C, Govindaraj S (2019) Management of an Unusual Intranasal Foreign Body Abutting the Cribriform Plate: A Case Report and Review of Literature. Clin Med Insights Ear Nose Throat 12: 1179550619858606.

7. Smith MM, Ishman SL (2018) Pediatric Nasal Obstruction. Otolaryngol Clin North Am 51: 971-985.

8. Bakshi SS (2019) A button battery in the nose. Intern Emerg Med 14: 185-186.
9. Cheng SY, Shih CP (2018) Button battery insertion in nose manifested as infraorbital cellulitis. Ear Nose Throat J 97: 274.

10. Dane S, Smally AJ, Peredy TR (2000) A truly emergent problem: button battery in the nose. Acad Emerg Med 7: 204-2006.

11. Watanabe K, Hatano GY, Aoki H, Okubo K (2013) The necessity of simple X-ray examination: a case report of button battery migration into the nasal cavity. Pediatr Emerg Care 29: 209-211.

12. Ryu CH, Jang YJ, Kim JS, Song HM (2008) Removal of a metallic foreign body embedded in the external nose via open rhinoplasty approach. Int J Oral Maxillofac Surg 37: 1148-1152.

13. Demiralp KO, Orhan K, Kurşun-Çakmak E, Gorurgoz C, Bayrak S (2018) Comparison of Cone Beam Computed Tomography and ultrasonography with two types of probes in the detection of opaque and non-opaque foreign bodies. Med Ultrason 20: 467-474.

14. Kaviani F, Javad Rashid R, Shahmoradi Z, Gholamian M(2014) Detection of foreign bodies by spiral computed tomography and cone beam computed tomography in maxillofacial regions. J Dent Res Dent Clin Dent Prospects 8: 166-171.

\section{Citation:}

Muriel JD, Escobedo MF, Cobo T, Cobo JL, Olay S, et al. (2019) Cone Beam Computed Tomography for Detection of Intranasal Foreign Bodies. J Dent Maxillofacial Res Volume 2(4): 1-3. 